\title{
Performance Evaluation of A2-A4-RSRQ and A3-RSRP Handover Algorithms in LTE Network
}

\author{
Hendrawan a, *, Ayu Rosyida Zain ${ }^{\text {b }}$, Sri Lestari Harja ${ }^{\text {c }}$ \\ ${ }^{a}$ School of Electrical Engineering \& Informatics \\ Institut Teknologi Bandung \\ Jalan Ganesha 10 \\ Bandung 40293, Indonesia \\ ${ }^{b}$ Politeknik Negeri Jakarta \\ Jl. Prof. Dr. G.A Siwabessy, Kampus Baru UI \\ Depok 16424, Indonesia \\ ${ }^{c}$ Universitas Pendidikan Indonesia \\ Jl. Dr. Setiabudhi No. 299 \\ Bandung 40154, Indonesia
}

\begin{abstract}
In LTE Network, users can move freely in the network through fast and seamless handover (HO). This research focuses on intra-LTE handover which occurs using interface X2 to move an EU between two eNBs, i.e. source eNB and target eNB without any changes in MME and SGW at EPC level. Two popular algorithms of intra-LTE handover namely A2-A4-RSRQ and A3-RSRP were evaluated and compared through simulations as well as direct measurements in the field. Simulation is conducted using NS3 simulation tool where performances of various scenarios from both algorithms were evaluated. The performance metrics studied include the average number of HOs that occur, throughput and optimized ratio. Simulations carried out for various scenarios in term of EU numbers, user speeds, and channel conditions. In addition, the results of one-month measurement of three eNBs were also presented. The measurement results are then compared and used to verify the simulation results. Furthermore, by using the optimizing ratio metric, the optimal pair of parameter values of Threshold as well as Offset and Handover Margin (HOM) along with Time-to-Trigger (TTT) are sought for the A2-A4-RSRQ and A3-RSRP respectively.
\end{abstract}

Keywords: LTE, Intra-LTE Handover, A2-A4-RSRQ, A3-RSRP.

\section{INTRODUCTION}

LTE is a cellular network standard of 3GPP which is the fourth generation of mobile cellular networks $(4 \mathrm{G})$ that implements all packet network architecture. This system is an evolution from the previous legacy mobile cellular networks $(3 \mathrm{G})$ designed to deliver higher data rate to allow high speed connections at anytime, anywhere [1]. LTE has a slimmer flat architecture compared to the previous generation, as shown in Figure 1 , which is mainly built from two main parts, Evolved Universal Terrestrial Radio Access (E-UTRAN) and Core Network, namely Evolved Packet Core Network (EPC) [1]. EUTRAN consists of a number of eNBs where interconnections between adjacent eNBs are built through the X2 interface. While EPC consists of the main components of $\mathrm{MME}$, SGW/PGW, where interconnection between eNB and EPC (MME, S-GW) is carried out via the S1 interface.

Meanwhile, User equipment (UE) on the LTE network, which can be any mobile device, is connected to the eNB via radio interface to access network services.

\footnotetext{
* Corresponding Author.

Email: hend@stei.itb.ac.id

Received: July 15, 2019

Accepted: December 4, 2019 ; Published: December 31, 2019

(C) 2019 PPET - LIPI
}

Users have mobility capabilities and can move freely in the LTE network across eNBs and through MME/SGWs via rapid and seamless handover $(\mathrm{HO})$ to guarantee the service continuity. Mobility is among the important Key Performance Indicators (KPIs) on LTE cellular networks, in addition to other KPIs such as accessibility, retainability, integrity and availability [2].

These capabilities can be achieved by the handover mechanism that is in keeping with the movement of the EU from one cell to another cell, it will be followed by the process of transferring eNB that serves the EU. Two handover types are known in LTE, i.e. Intra-LTE Handover and Inter-LTE Handover. In the first category that will be the focus of this research, handover occurs using interface $\mathrm{X} 2$ to move EU from a source eNB (SeNB) to a target eNB (T-eNB) without any changes in MME and SGW at EPC level.

More attention is given to Intra-LTE Handover because more handovers take place more frequently through eNBs than across core networks because the area covered by $\mathrm{MME} / \mathrm{SGW}$ operates for a large number of eNBs [3]. Furthermore, Intra-LTE handover procedure can be apportioned into three phases : handover preparation, handover execution and handover completion [4]. Handover is initiated by the EU by sending a measurement report that is triggered by one or more events, that is conditions where the results of measuring channels in the form of RSRP and or RSRQ 
meet some certain criteria. The RSRP (Reference Signal Received Power) measurement provides cell-specific signal strength metric defined for a specific cell as the linear average received power (in Watts) of the signals that carry cell-specific Reference Signals (RS) within the considered measurement frequency bandwidth [5].

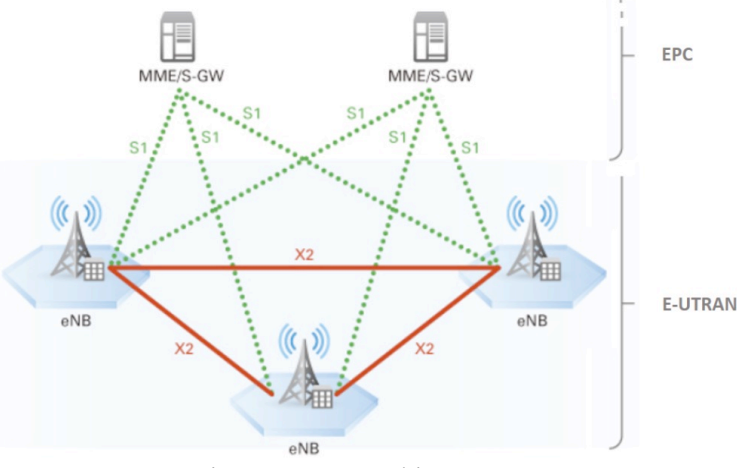

Figure 1. LTE Architecture [1]

TABLE 1

EVENTS AND TRIGGERING CONDITION

\begin{tabular}{|c|l|}
\hline Event & \multicolumn{1}{|c|}{ Trigerring Conditions } \\
\hline A2 & $\begin{array}{l}\text { Signal quality in the serving cell }<\text { than a specified } \\
\text { threshold }\end{array}$ \\
\hline A3 & $\begin{array}{l}\text { Signal quality in neighbouring cell }>\text { than that in the } \\
\text { serving cell }\end{array}$ \\
\hline A4 & $\begin{array}{l}\text { Signal quality }>\text { than a specified threshold in } \\
\text { neighbouring cell }\end{array}$ \\
\hline
\end{tabular}

In addition, Reference Signal Received Quality (RSRQ) considers the interference level into account and is defined as the multiplication of the number of blocks of LTE carriers with RSRP divided by the total received wide-band power (RSSI). Based on signal quality measurements in term of RSRP and RSRQ, there are three identifiable events, which can be used for handover decisions, namely Event A2, A3 and A4 as shown in Table 1.

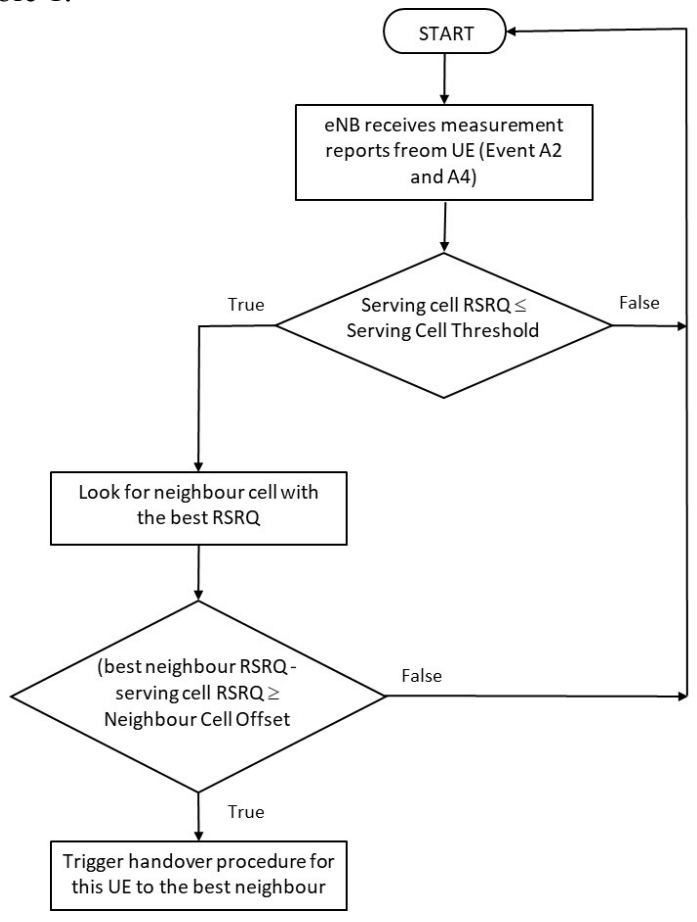

Figure 2. A2-A4-RSRQ handover algorithm

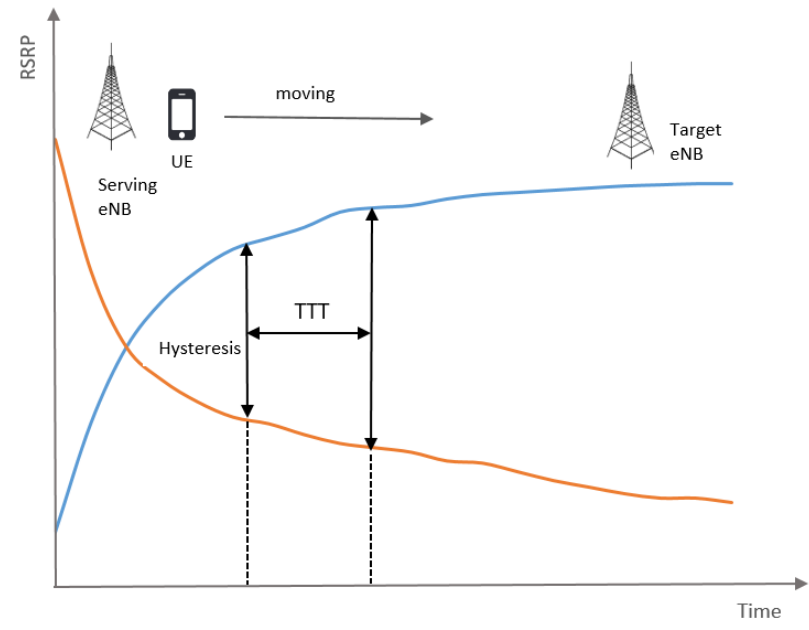

Figure 3. A3-RSRP handover algorithm

There are two handover algorithms commonly used in LTE networks based on the above events, i.e. A2-A4RSRQ and A3-RSRP. Explanation of the first Algorithm which is built on the event of A2 and A4, can be seen on the flowchart in the Figure 2.

On the otherhand, the second $\mathrm{HO}$ algorithm is initiated if the serving eNB receives an A3 event report. Then there are two variables that will determine the handover will occur, namely Hysteresis and Time-toTrigger (TTT) timer. The former variable which also called handover margin (HOM) is a constant threshold value that shows the difference between RSRP service and target RSRP. Handover occurs if HOM is greater than a certain value for a period of time of at least TTT. The working method of the A3-RSRP process is illustrated as shown in Figure 3.

In this study, the two algorithms mentioned earlier were evaluated and compared using simulations and also direct measurements in the field. Simulation uses NS3 simulation tool and evaluates various performance scenarios from both algorithms. The performance metrics studied included the average number of HOs that occur for each EU during a given period of time, throughput and optimized ratio. Simulations carried out for various scenarios include variations in EU numbers, user speeds, and channel conditions (with and without fading). In addition to the simulation, the results of a one-month measurement of three eNBs were also evaluated. The measurement results are then compared and used to verify the simulation results. Furthermore, by using the optimizing ratio metric, the optimal values for the Serving Cell Threshold (SCT) as well as Neighbour Cell Offset (NCO) for the A2-A4-RSRQ algorithm and the values of Handover Margin (HOM) or Hysteresis along with Time-to-Trigger (TTT) variables for the A3-RSP algorithm are sought.

Some researchers have conducted research related to the A2-A4-RSRQ and A3-RSRP handover algorithms on LTE networks. Generally the research is carried out only on one algorithm, whether A3-based event or A2-A4 event. [6]-[9]. Although there is also a researcher who make comparisons between the two algorithms [10]. Furthermore, most studies are based on simulations, generally using NS3 simulator, though there are also some researchers using other simulation tools such as 
Matlab [11]-[12], or other simulation languages such as $\mathrm{C}++[13]$. Some researchers also conducted research related to other aspects of the effect of handover on LTE. For example, [12] evaluates the TCP and UDP transmission performance due to the effects of handover implementation on the LTE network. While other researcher conducted a study related to handover on High Speed Railway system [14]. In addition, another researcher [15] focused on optimization of RSRP-based handover parameters based on user behavior.

Conversely, there are no research have been reported that verify or compare the results of the simulation with the results of real measurements related to the performance of the handover algorithms. Likewise, none of the studies that have been conducted have seen the influence of channel conditions on the evaluation of simulation results. To cover these shortcomings, this research completes the study by validating the simulation results with the results of direct measurements taken from the interconnection of three eNBs directly in the field. Additionally, optimization to obtain various parameters of the A2-A4-RSRQ and A3-RSRP algorithms is done that are validated using measurement results.

\section{MethoD}

\section{A. Simulation Method}

To evaluate various handover scenarios on LTE network, NS3 LTE module was used [16]. The simulation configuration scheme carried out refers to the LENA model as shown in the Figure 4. Simulation uses seven macrocell with three cells each where the intermacrocell distance is $500 \mathrm{~m}$. Furthermore, the EU is distributed randomly around the site and automatically connected to the network. All parameters used in the simulation and their corresponding values are given in Table 2.

After being set with these parameter values, the EU will move at speeds varying from 20 up to $120 \mathrm{~km}$ per hour, where the speed is increased gradually with an increase of $20 \mathrm{~km} /$ hour. Likewise the EU number will be varied and two canal conditions are considered, namely by considering the fading effect and without any fading effect.

The fading model used in the simulation refers to 3GPP fading propagation conditions [17]. In this study, the fading model used is vehicular fading model (Extended Vehicular A model - EVA) and urban fading model (Extended Typical Urban model - ETU) [17] with user speeds $20-60 \mathrm{~km} / \mathrm{h}$ and $60-120 \mathrm{~km} / \mathrm{h}$ respectively.

Furthermore, the parameters related to the handover algorithm, i.e. Serving Cell Threshold, Neighbour Cell Offset, Hysteresis and Time-to-Trigger are varied to observe the effect on various scenarios as a function of the number and speed of user movements and channel conditions. The optimum value of the handover algorithm parameters is also sought and identified. Performance metrics used for evaluation include Throughput, ANOH and Optimize Ratio.

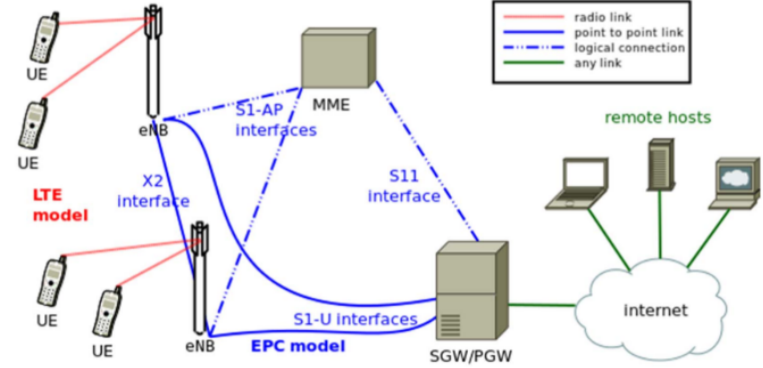

Figure 4. LENA model overview [16].

TABLE 2.

SIMULATION PARAMETERS

\begin{tabular}{|c|c|c|}
\hline Parameter Name & Value & Description \\
\hline simTime & 50 & $\begin{array}{c}50 \text { seconds } \\
\text { simulation duration }\end{array}$ \\
\hline nMacroEnbSites & 7 & $\begin{array}{c}\text { Number of microcell } \\
\text { sites (each site has } 3 \\
\text { cells) }\end{array}$ \\
\hline nMacroEnbSitesX & 2 & $\begin{array}{l}\text { The microcell sites } \\
\text { will be positioned in } \\
\text { a } 2-3-2 \text { formation }\end{array}$ \\
\hline interSiteDistance & 500 & $\begin{array}{c}500 \mathrm{~m} \text { distance } \\
\text { between adjacent } \\
\text { microcell sites }\end{array}$ \\
\hline $\begin{array}{c}\text { macroEnbTxPow } \\
\text { erDbm }\end{array}$ & 46 & $\begin{array}{c}46 \mathrm{dBm} \text { Tx power for } \\
\text { each microcell }\end{array}$ \\
\hline epc & 1 & Enable EPC mode \\
\hline epcDl & 1 & $\begin{array}{c}\text { Enable full-buffer } \\
\text { DL traffic }\end{array}$ \\
\hline epcUl & 1 & $\begin{array}{c}\text { Enable full-buffer } \\
\text { UL traffic }\end{array}$ \\
\hline useUDP & 0 & $\begin{array}{c}\text { Disable UDP Traffic } \\
\text { and enable TCP } \\
\text { instead }\end{array}$ \\
\hline macroUeDensity & 0.00002 & $\begin{array}{l}\text { Determines number } \\
\text { of UEs (41 UE and } \\
0.00001 \text { for } 20 \mathrm{UE} \text { ) }\end{array}$ \\
\hline $\begin{array}{l}\text { outdoorUeMinSp } \\
\text { eed }\end{array}$ & 16.6667 & $\begin{array}{c}\text { Minimum UE } \\
\text { movement speed in } \\
\mathrm{m} / \mathrm{s}(60 \mathrm{kmph}), 30 \\
\mathrm{kmph}, 120 \mathrm{kmph}\end{array}$ \\
\hline $\begin{array}{c}\text { outdoorUeMaxSp } \\
\text { eed }\end{array}$ & 16.6667 & $\begin{array}{c}\text { Maximum UE } \\
\text { movement speed in } \\
\mathrm{m} / \mathrm{s}(60 \mathrm{kmph}), 30 \\
\mathrm{kmph}, 120 \mathrm{kmph}\end{array}$ \\
\hline Fadingtrace & $\underset{3 \mathrm{kmph}}{\operatorname{fading} \text { trace_EPA_ }}$ & $\begin{array}{c}\text { fading_trace_EPA_3 } \\
\text { kmph, } \\
\text { fading_trace_EVA_6 } \\
\text { 0kmph, } \\
\text { fading_trace_ETU_3 } \\
\text { kmph }\end{array}$ \\
\hline $\begin{array}{l}\text { macroEnbBandwi } \\
\text { dth } \\
\end{array}$ & 25 & $\begin{array}{c}5 \mathrm{MHz} \text { DL and UL } \\
\text { bandwidth }\end{array}$ \\
\hline
\end{tabular}

\section{B. Performance Metrics}

Performance of the two handover implementations alluded above is evaluated based on the average number of handovers per EU per second (ANOH), Throughput of the system and Optimization Ratio. A detailed description of each metric used is explained as follows.

$\mathrm{ANOH}$

$\mathrm{ANOH}$ is the average number of handovers that occur in one second for each EU and can be expressed mathematically as: 


$$
\begin{gathered}
X[k]=\sum_{n=0}^{N-1} x[n] \exp \left(\frac{-i 2 \pi k n}{n}\right), \\
A N O H=\left(\frac{H O_{\text {Total }}}{N \times T}\right),
\end{gathered}
$$

Where $H O_{\text {total }}$ is the total number of successful handovers, while $N$ and $T$ correspondingly refer to the number of EU and total simulation time in second. Handover is said to be successful when EU moves from eNB source to eNB target with continuous service without breaking or terminating data transmission.

\section{Cell Throughput}

Cell throughput is defined as the total number of bits received by the EU per second and measured on an eNB, mathematically stated as follows:

$$
\text { CellThroughput }=\frac{1}{T} \sum_{n=1}^{N} \sum_{t=1}^{T} \operatorname{tput}_{j}(t)
$$

Where $t_{p u t}(t)$ is the total size of the packet received (in bits) of the user $n$ at the time interval $t$, while $T$ is the total simulation time and $N$ is the total number of users. Throughput of the system in total is the sum of all cell throughputs as stated below:

$$
\text { Throughput }_{\text {Total }}=\sum_{c-1}^{C} \text { CellThroughput }_{c}
$$

Where CellThroughpt $t_{c}$ is the CellThroughput of cell $c$ and $C$ is total cell in the simulation (7 in our case).

\section{Optimize Ratio}

The optimization parameter shows how well the handover algorithm performs, which is the ratio between Total Throughput and Average number of handover per UE per second, which can be expressed as follows:

$$
\text { OptimizeRatio }=\left(\frac{\text { Throughput }_{\text {Total }}}{A N O H}\right)
$$

Optimize Ratio is a performance metric that can be used for A2-A4-RSRQ and A3-RSRP handover algorithms and is calculated for certain user (UE) speed scenarios. In the former algorithm Optimize Ratio is calculated for particular Neighbor Cell Offset and Serving Cell Threshold values and the latter for particular Hysteresis and Time-to-Trigger values. Hence, Optimize Ratio will produce different values for different EU speeds and different settings of handover parameters. Therefore, in the handover algorithm optimization process, the handover parameter values that provide optimum values for certain EU speeds must be looked for.

\section{Measurement Method}

In this study, direct measurements were carried out to evaluate the performance of the X2-based handover mechanism on existing LTE networks in one of the cellular operators in Indonesia located in the Cirebon area. Measurements were made on three eNBs where observations were conducted on an hourly basis for one month by observing measurement parameters, namely Throughput, Average Number of Handover (ANOH) and Optimize Ratio. Details of the measurement scenario and the handover parameters used are shown in Table 3. Measurements are made through the Centralized Task Management mechanism of the NMS through the U2000 device which manages and coordinates all the tasks to collect network performance data within a specified period. Handover performance is observed by setting hysteresis, time-to-trigger, SCT and Offset parameters with values as shown in Table 1 .

The existing network that is monitored using TTT and Hysteresis as a trigger for the occurrence of the X2 handover, where their value is $480 \mathrm{~ms}$ and $2 \mathrm{~dB}$ respectively. Besides, the provider also sets the threshold and offset values i.e. Threshold $=30 \mathrm{~dB}$ and Offset $=2 \mathrm{~dB}$. The measurement results observed are the Throughput value, Average Number of Handover (ANOH) and Optimize Ratio. The evaluation results are then used as a comparison value to verify the simulation results. The measurement results for Downlink (DL) Throughput for each eNB are shown in Figure 6. Because the DL Throughput varies for each hourly observation in one month, the measurement results are described in the Box and Whisker chart. Using this chart, the shape of the distribution can be shown and summary of a set of onemonth data in term of the minimum, first quartile, median, average, third quartile, and maximum can be observed.

From the measurement results, the value of DL throughput for each eNB is $15.99 \mathrm{MBps}, 13.27 \mathrm{MBps}$ and 16.39 MBps respectively. So that the overall DL Throughput for the three eNB is $15.22 \mathrm{MBps}$. For other parameters related to the performance of the handover algorithm, that is $\mathrm{ANOH}$ and Optimize ratio, the average values of the three eNBs are 0.01 and 1077.32 respectively.

TABLE 3 .

MEASUREMENT SCENARIO AND PARAMETERS USED

\begin{tabular}{|c|c|}
\hline Parameter Name & Value \\
\hline number of eNB & 3 \\
\hline number of Cell per eNB & 3 \\
\hline distance between eNB & $2 \mathrm{~km}$ \\
\hline eNB Power & $43 \mathrm{dBm}$ \\
\hline Bandwidth & 46 \\
\hline Number of UE & $2 \mathrm{~dB}$ \\
\hline Hysteresis & $480 \mathrm{~ms}$ \\
\hline Time-To-Trigger & $30 \mathrm{~dB}$ \\
\hline ServingCellThreshold & $2 \mathrm{~dB}$ \\
\hline NeighbourCellOffset & (eand DL \\
\hline
\end{tabular}

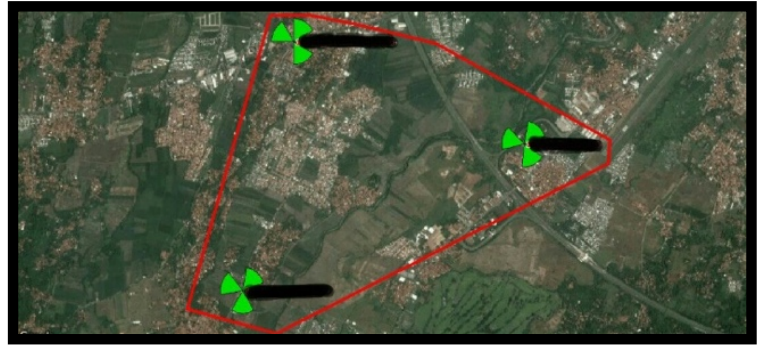

Figure 5. Map of the Three eNBs used for Measurement 


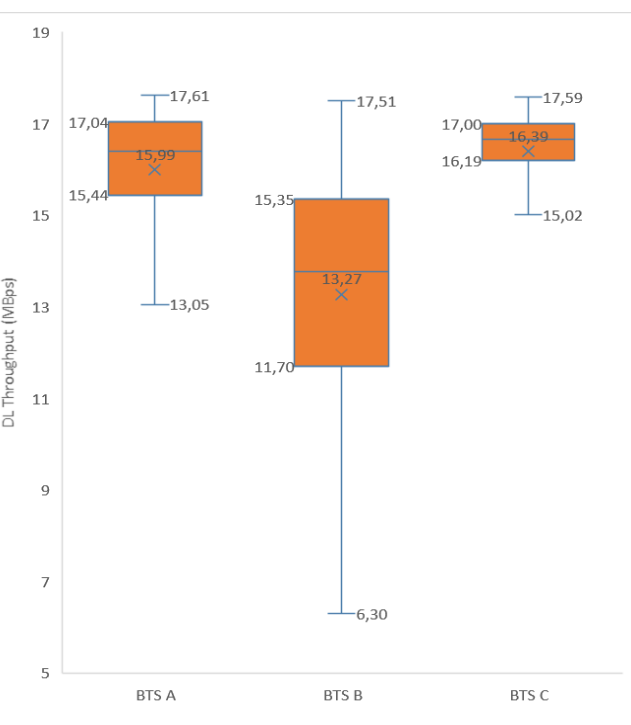

Figure 6. Box and Whisker chart for DL Throughput

\section{HO Parameter Optimization}

From the two handover algorithms observed, namely RSRP-based A3-RSRP and RSRQ-based A2-A4-RSRQ, the optimum value of the parameters that provide the best performance will be sought. The handover parameters optimized in the RSRP Algorithm are Hysteresis and Time-to-Trigger (TTT), while in the RSRQ algorithm is a Serving Cell Thershold and a Cell Offset Neighbor. Whereas the best performance measure that is the cost function of the optimization process is Optimize Ratio as formulated in equation (5). The values of the handover algorithm parameters that will be tested are valid parameter values in their range as follows.

\section{A3-RSRP Algorithm}

- $\quad T T T=256 \mathrm{~ms}, 320 \mathrm{~ms}, 480 \mathrm{~ms}, 512 \mathrm{~ms}, 640 \mathrm{~ms}$.

- Hysteresis $=1 \mathrm{~dB}, 2 \mathrm{~dB}, 3 \mathrm{~dB}, 4 \mathrm{~dB}, 4 \mathrm{~dB}, 5 \mathrm{~dB}, 6 \mathrm{~dB}$, $7 \mathrm{~dB}, 8 \mathrm{~dB}, 9 \mathrm{~dB}, 10 \mathrm{~dB}, 11 \mathrm{~dB}, 12 \mathrm{~dB}, 13 \mathrm{~dB}, 14 \mathrm{~dB}$, $15 \mathrm{~dB}$

2. A2-A4-RSRQ Algorithm

- ServingCellThreshold $=28 \mathrm{~dB}, 29 \mathrm{~dB}, 30 \mathrm{~dB}, 31 \mathrm{~dB}$, $32 \mathrm{~dB}$

- NeighbourCellOffset $=1 \mathrm{~dB}, 2 \mathrm{~dB}, 3 \mathrm{~dB}, 4 \mathrm{~dB}, 4 \mathrm{~dB}, 5$ $\mathrm{dB}, 6 \mathrm{~dB}, 7 \mathrm{~dB}, 8 \mathrm{~dB}, 9 \mathrm{~dB}, 10 \mathrm{~dB}, \mathrm{~dB}, 12 \mathrm{~dB}, 13 \mathrm{~dB}$, $14 \mathrm{~dB}, 15 \mathrm{~dB}$.

The EU number for this test is 46 which is randomly distributed to the nearest eNBs. EU speed is set randomly also from a minimum speed of $10 \mathrm{Kmph}$ to a maximum speed of $120 \mathrm{Kmph}$. From this optimization process, a combination of TTT and Hysteresis values for the A3RSRP algorithm and Serving Cell Threshold and Neighbour Cell Offset values for the A2-A4-RSRQ algorithm which produce the best Optimize Ratio for EU movements in the range of 10 to $120 \mathrm{Kmph}$ will be obtained.

\section{Result AND Discussion}

\section{A. Simulation}

\section{A2-A4-RSRQ Algorithm}

For evaluation of the A2-A4-RSRQ algorithm the scenarios evaluated include various variations of the $\mathrm{EU}$ number, EU movement speed, and channel conditions (with and without fading). The results of the simulation that show the performance of the algorithm in term of $A N O H$ and Optimize Ratio are shown in the Figure7 up to Figure 14 below.

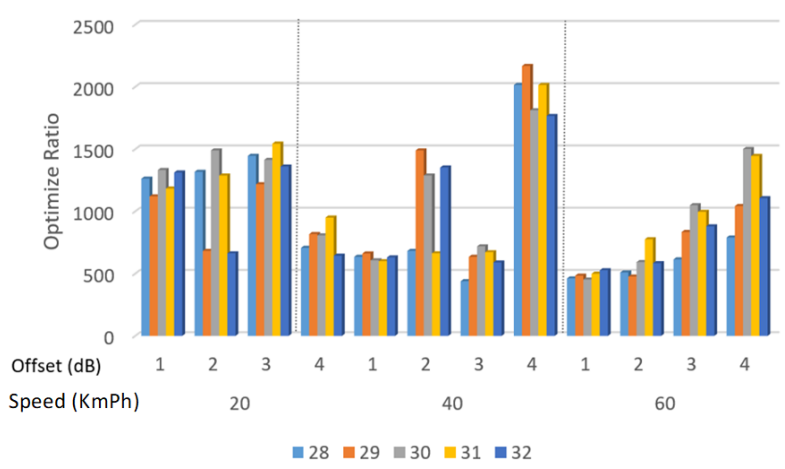

(a)

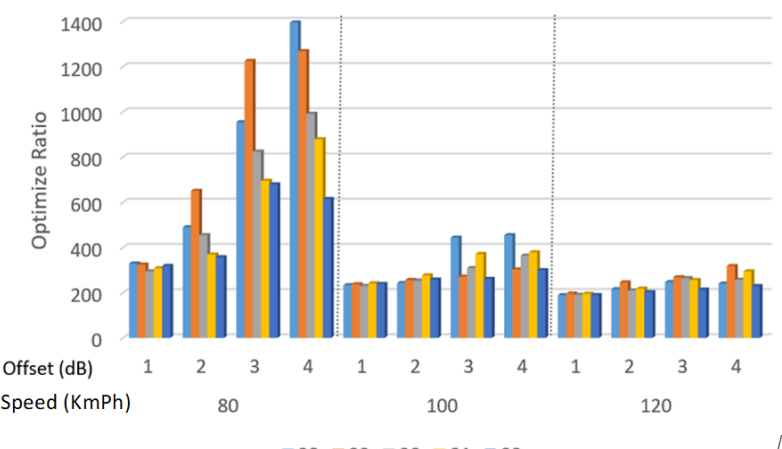

(b)

Figure 7. Optimized Ratio for various Offset and Threshold parameter values at various speeds of EU movements (a) Low speed: 20-60

Kmph, and (b) high-speed: 80-120 Kmph of 20 UEs without considering Fading Effect.

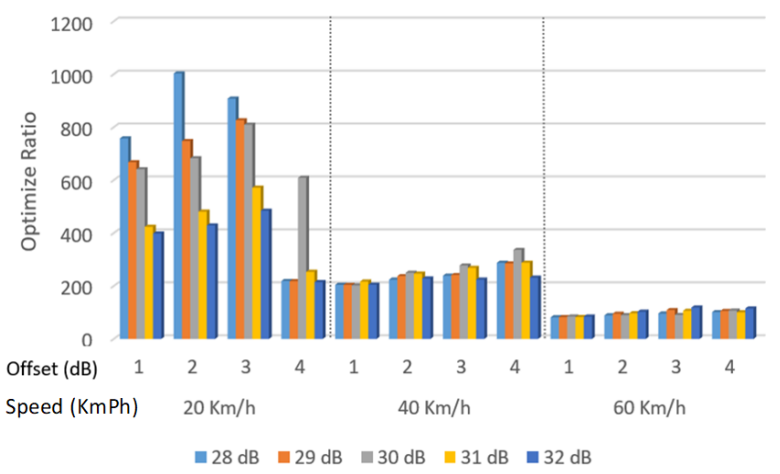

(a)

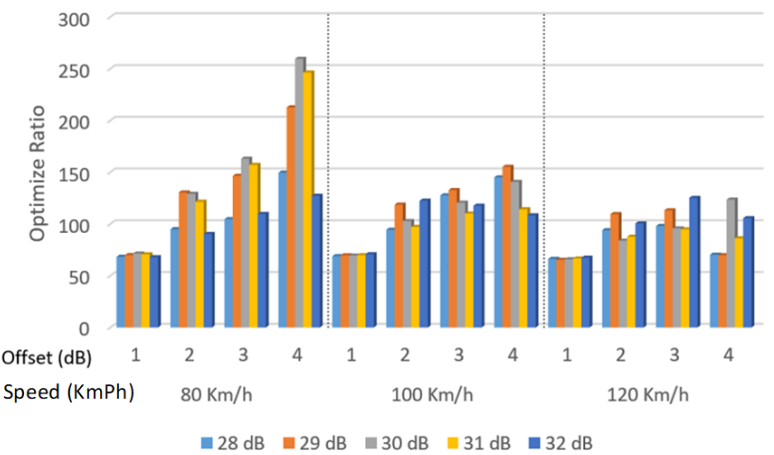

(b)

Figure 8. Optimized Ratio for various Offset and Threshold parameter values at various speeds of EU movements (a) Low speed: 20-60 Kmph, and (b) high-speed: 80-120 Kmph of 20 UEs by considering Fading. 


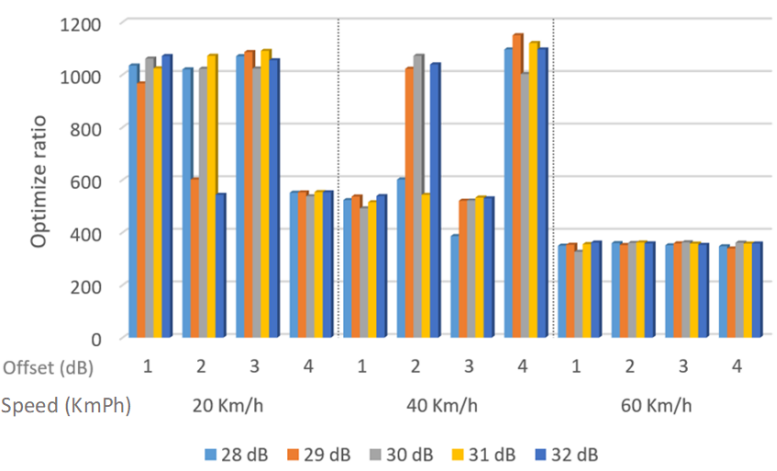

(a)

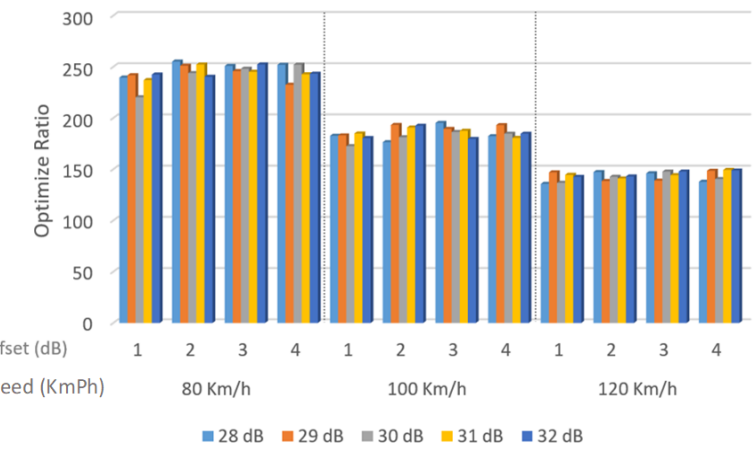

(b)

Figure 9. Optimized Ratio for various Offset and Threshold parameter values at various speeds of EU movements (a) Low speed: 20-60 Kmph, and (b) high-speed: $80-120 \mathrm{Kmph}$ of 41 UEs without considering Fading Effect.

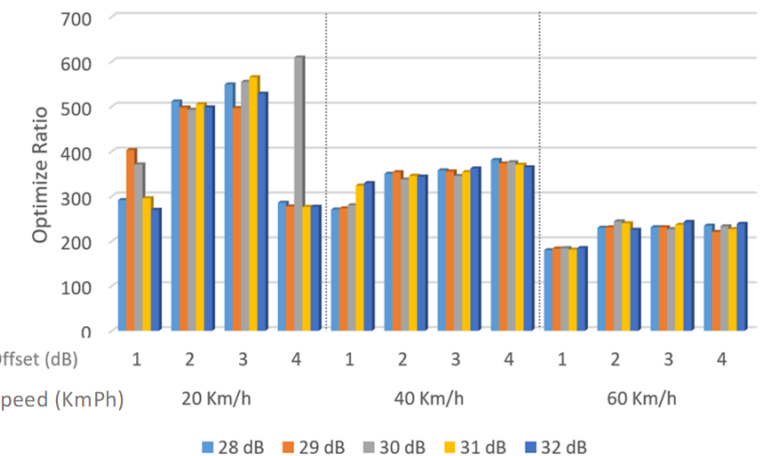

(a)

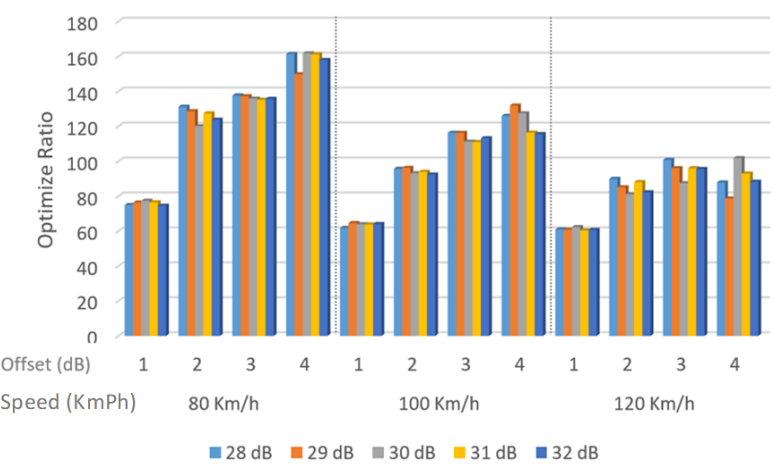

(b)

Figure 10. Optimized Ratio for various Offset and Threshold parameter values at various speeds of EU movements (a) Low speed: 20-60 Kmph, and (b) high-spedd: $80-120 \mathrm{Kmph}$ of 41 UEs by considering Fading.

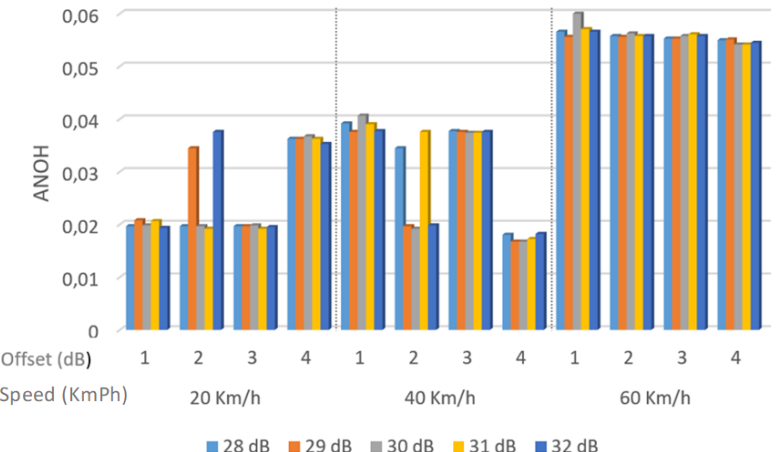

(a)

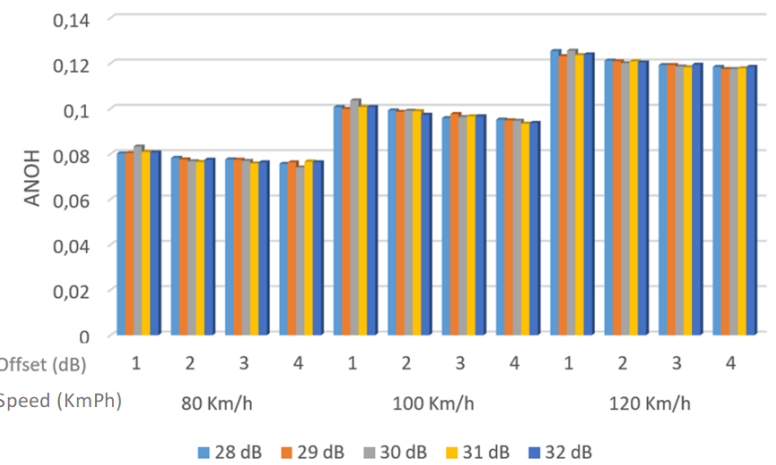

(b)

Figure 11. ANOH for various Offset and Threshold parameter values at various speeds of EU movements (a) Low speed: 20-60 Kmph, and (b) high-speed: 80-120 Kmph of 20 UEs without considering Fading Effect.

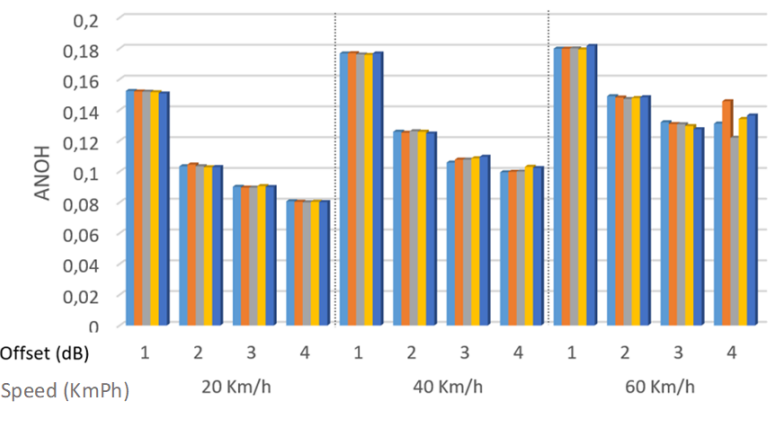

(a)

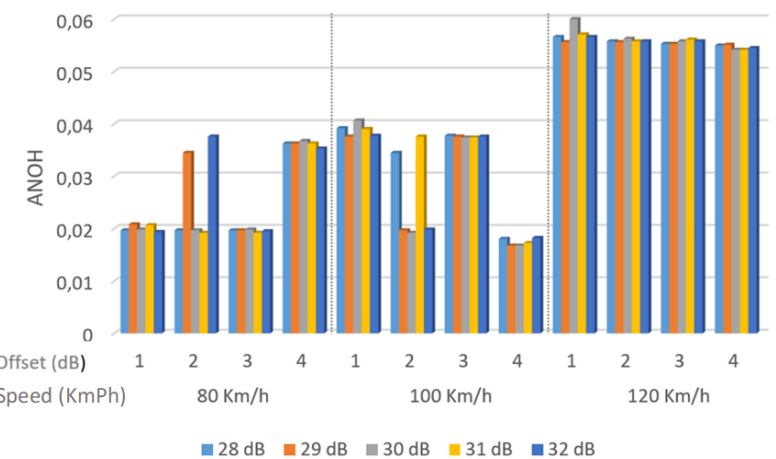

(b)

Figure 12. ANOH for various $O f f$ set and Threshold parameter values at various speeds of EU movements (a) Low speed: 20-60 Kmph, and (b) high-speed: 80-120 Kmph of 20 UEs by considering Fading Effect. 

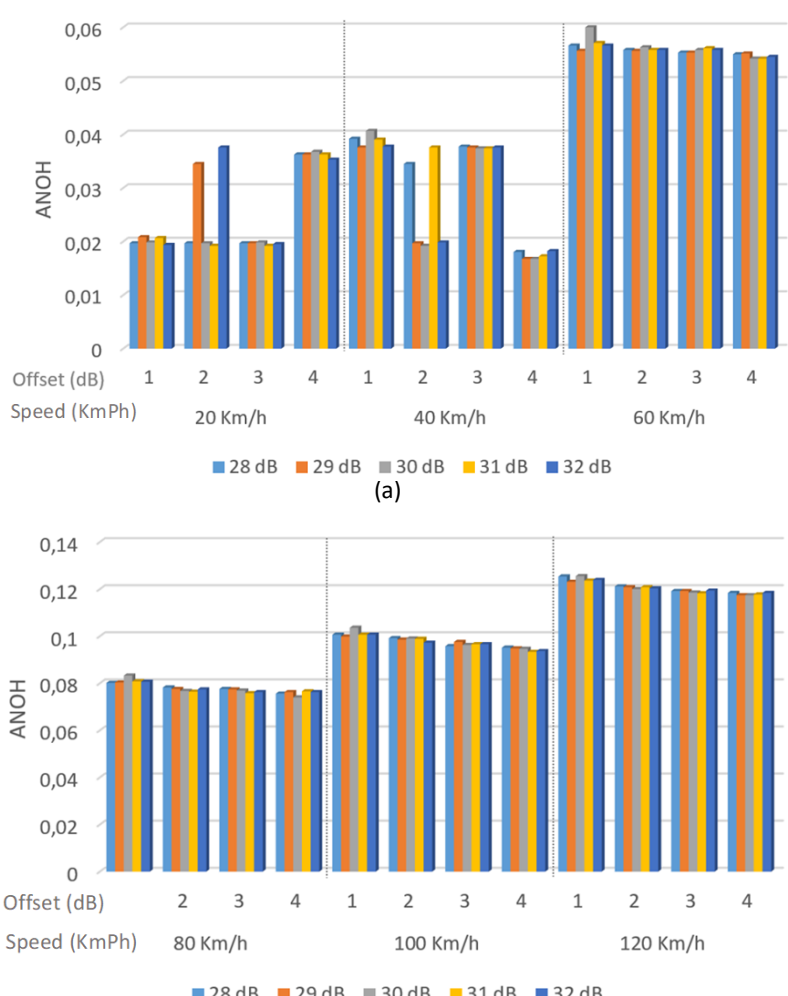

(b)

Figure 13. ANOH for various Offset and Threshold parameter values at various speeds of EU movements (a) Low speed: 20-60 Kmph, and (b) high-speed: 80-120 Kmph of 41 UEs without considering Fading Effect.

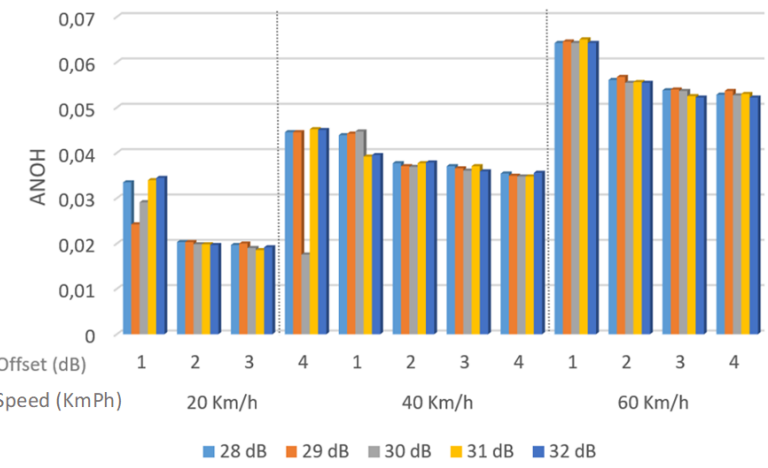

(a)

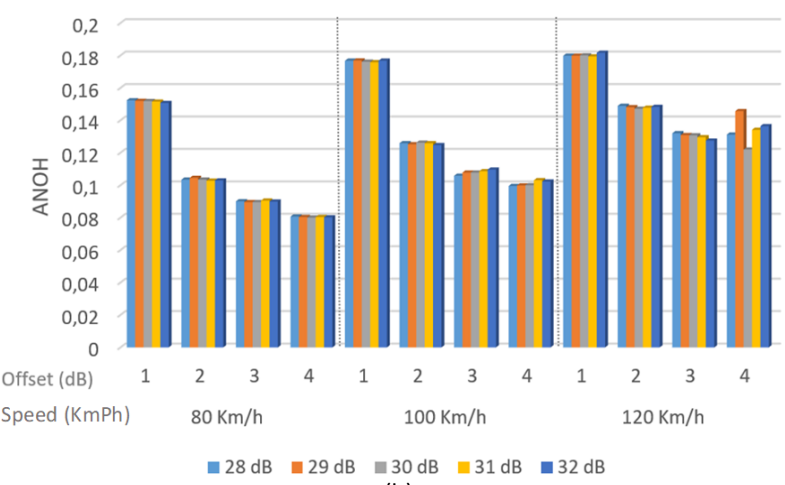

(b)

Figure 14. ANOH for various Offset and Threshold parameter values at various speeds of EU movements (a) Low speed: 20-60 Kmph, and (b) high-spedd: 80-120 Kmph of 41 UEs by considering Fading Effect.
TABLE 4

SIMULATION RESUlts FOR VARIOUS SCENARIOS FOR THE A2-A4RSRQ ALGORITHM

\begin{tabular}{|c|c|c|c|c|}
\hline \multirow{2}{*}{$\begin{array}{c}\text { UE } \\
\text { Movement } \\
\text { Speed }\end{array}$} & $\begin{array}{c}|c| \\
\text { Fading User }\end{array}$ & $\begin{array}{c}\text { 20 User } \\
\text { [Threshold;Offset] }\end{array}$ & \multicolumn{2}{c|}{ [Threshold;Offset] } \\
\cline { 2 - 5 } & $\begin{array}{c}\text { Effect } \\
\text { considered }\end{array}$ & $\begin{array}{c}\text { not } \\
\text { considered }\end{array}$ & $\begin{array}{c}\text { Effect } \\
\text { considered }\end{array}$ & $\begin{array}{c}\text { Effect } \\
\text { is not } \\
\text { consi- } \\
\text { dered }\end{array}$ \\
\hline $20 \mathrm{kmph}$ & {$[32 ; 3]$} & {$[32 ; 4]$} & {$[28 ; 2]$} & {$[29 ; 4]$} \\
\hline $40 \mathrm{kmph}$ & {$[28 ; 4]$} & {$[28 ; 2]$} & {$[30 ; 4]$} & {$[31 ; 4]$} \\
\hline $60 \mathrm{kmph}$ & {$[31 ; 2]$} & {$[30 ; 3]$} & {$[32 ; 3]$} & {$[30 ; 4]$} \\
\hline $80 \mathrm{kmph}$ & {$[28 ; 4]$} & {$[28 ; 2]$} & {$[30 ; 4]$} & {$[28 ; 4]$} \\
\hline $100 \mathrm{kmph}$ & {$[29 ; 4]$} & {$[29 ; 4]$} & {$[29 ; 4]$} & {$[28 ; 4]$} \\
\hline $120 \mathrm{kmph}$ & {$[30 ; 4]$} & {$[31 ; 4]$} & {$[32 ; 3]$} & {$[29 ; 4]$} \\
\hline
\end{tabular}

From the results in Figure 7 to 14, the best Serving Cell Threshold and Cell Offset Neighbor parameter values for various speed and channel conditions are shown in Table 4.

\section{A3-RSRP Algorithm}

In like manner, for evaluation of the A3-RSRP algorithm the scenarios evaluated include various variations of the EU number, EU movement speeds, and channel conditions (with and without fading). The results of the simulation that show the performance of the algorithm in term of $A N O H$ and Optimize Ratio are shown in the Figure 15 up to Figure 22 below.

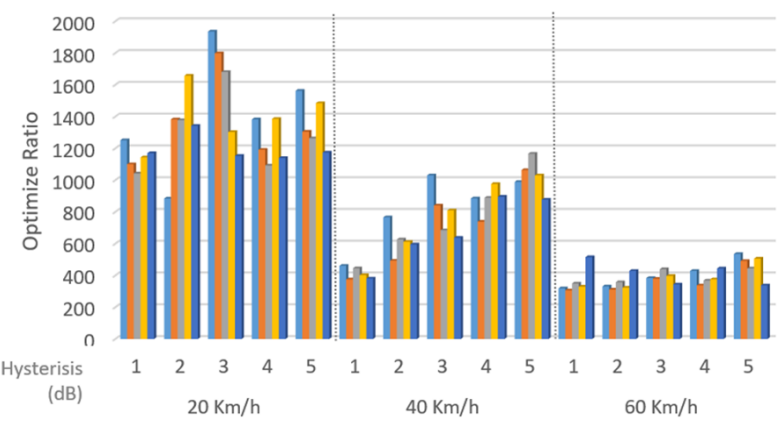

(a)

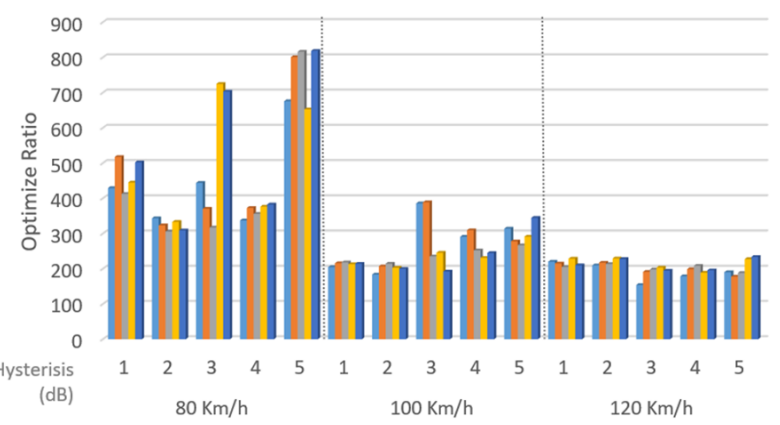

(b)

Figure 15. Optimized Ratio for various Hysteresis and TTT parameter values at various speeds of EU movements (a) Low speed: 20-60 $\mathrm{Kmph}$, and (b) high-speed: $80-120 \mathrm{Kmph}$ of 20 UEs without considering Fading Effect 

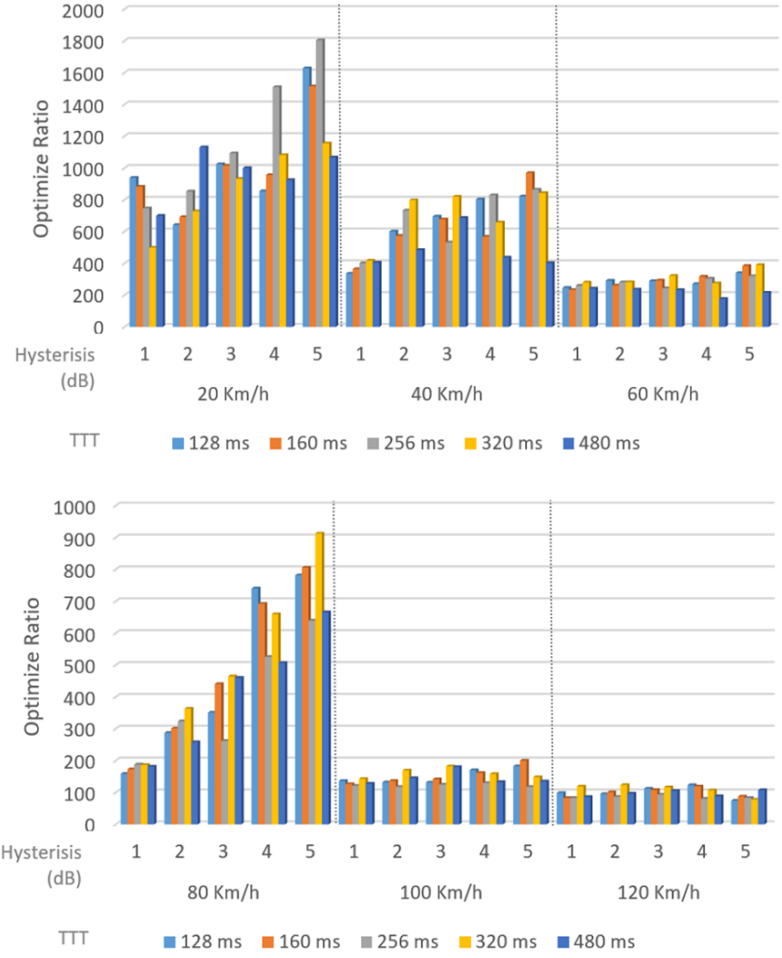

(b)

Figure 16. Optimized Ratio for various Hysteresis and TTT parameter values at various speeds of EU movements (a) Low speed: 20-60 Kmph, and (b) high-speed: $80-120 \mathrm{Kmph}$ of 20 UEs by considering Fading Effect.

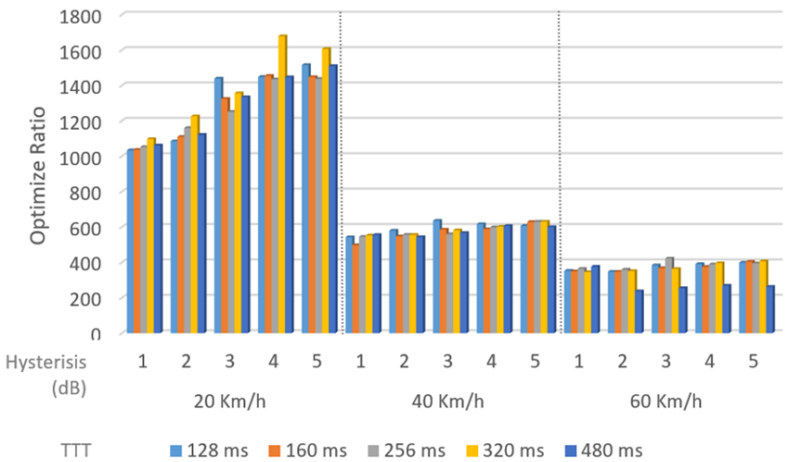

(a)

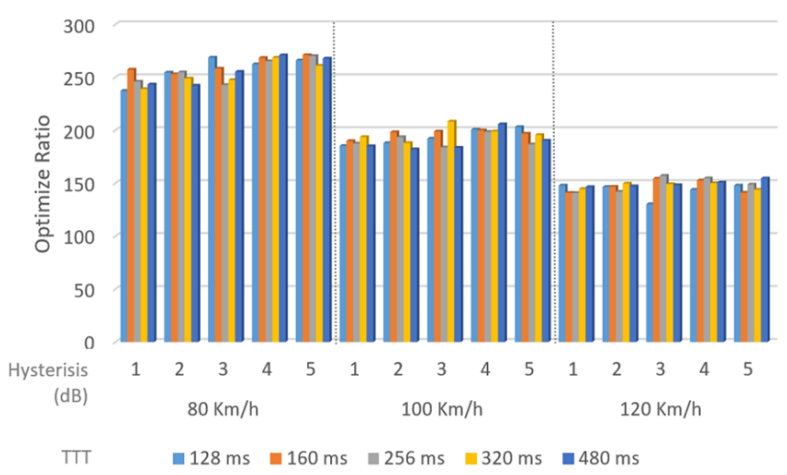

(b)

Figure 17. Optimized Ratio for various Hysteresis and TTT parameter values at various speeds of EU movements (a) Low speed: 20-60 Kmph, and (b) high-speed: 80-120 Kmph of $41 \mathrm{UEs}$ without considering Fading Effect.

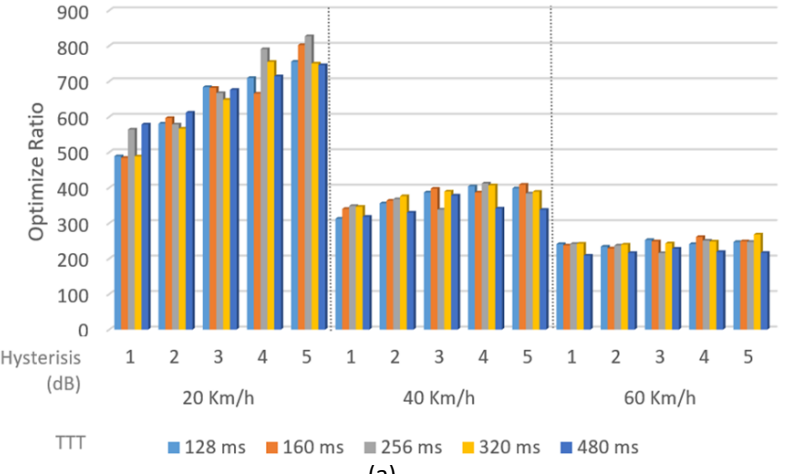

(a)

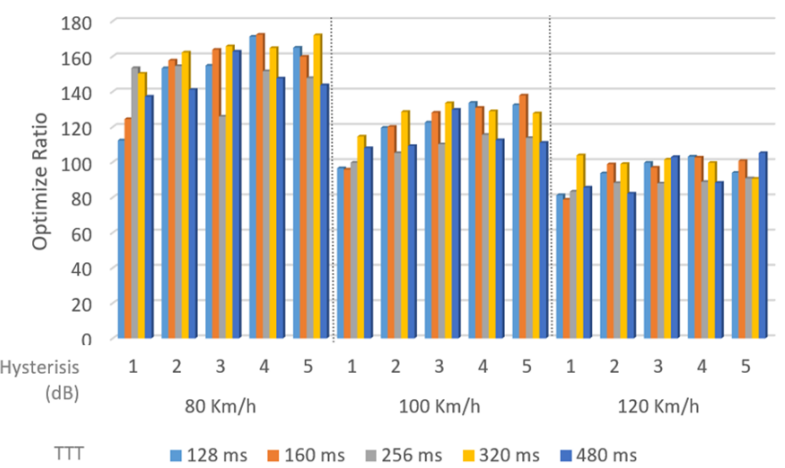

(b)

Figure 18. Optimized Ratio for various Hysteresis and TTT parameter values at various speeds of EU movements (a) Low speed: 20-60 Kmph, and (b) high-speed: 80-120 Kmph of 41 UEs by considering Fading Effect.

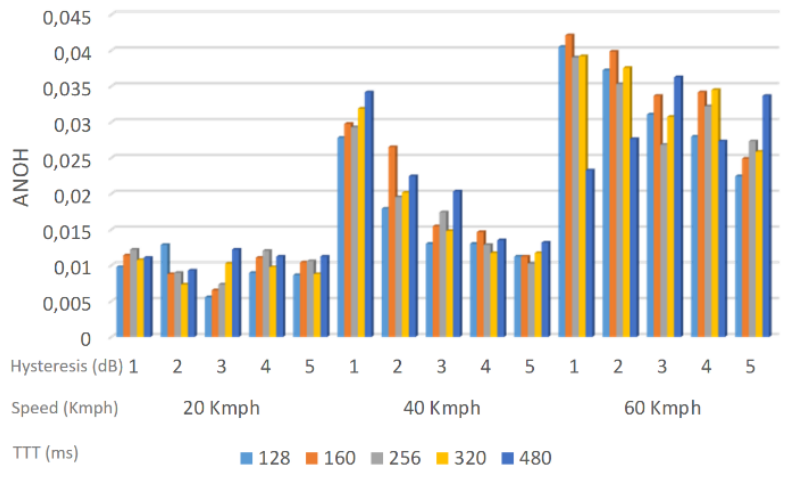

(a)

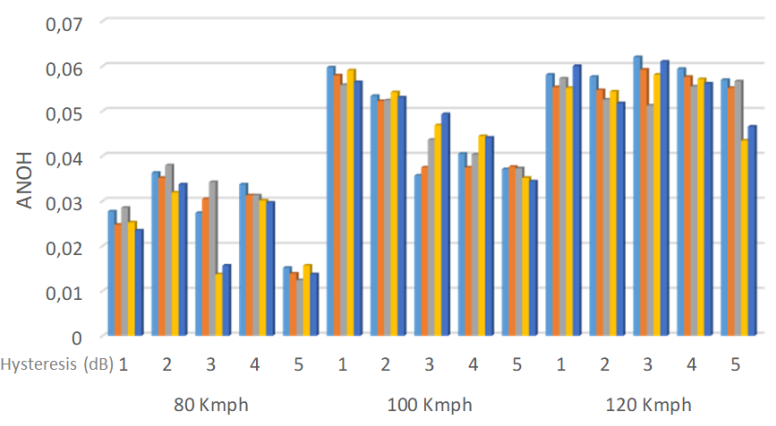

$\pi$ (ms)

- $128=160=256=320=480$

(b)

Figure 19. ANOH for various Hysteresis and TTT parameter values at various speeds of EU movements (a) Low speed: 20-60 Kmph, and (b) high-speed: 80-120 Kmph of 20 UEs without considering Fading Effect 


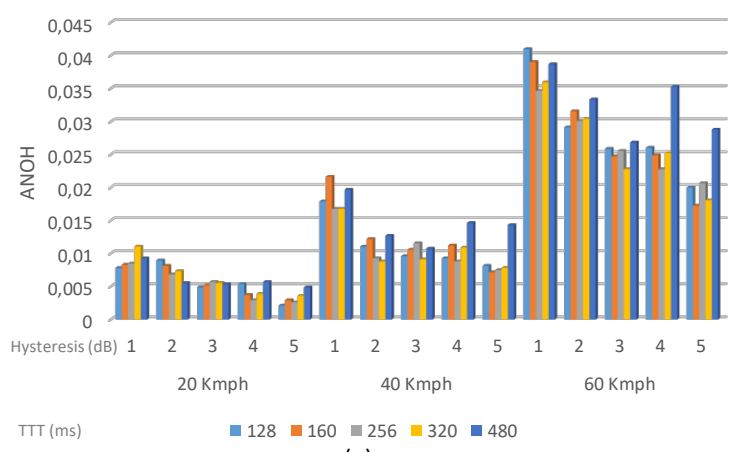

(a)

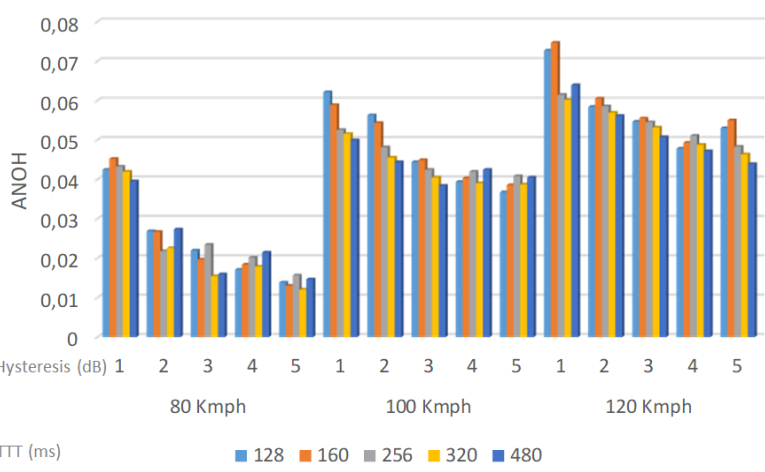

(b)

Figure 20. ANOH for various Hysteresis and TTT parameter values at various speeds of EU movements (a) Low speed: 20-60 Kmph, and (b) high-speed: 80-120 Kmph of 20 UEs by considering Fading Effect.

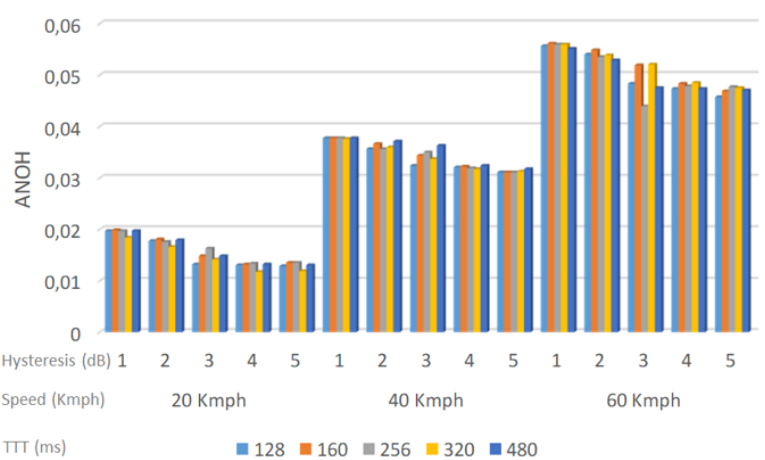

(a)

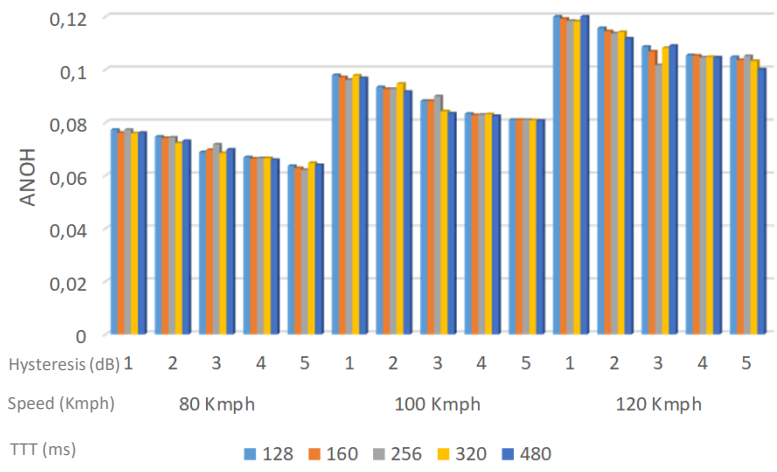

(b)

Figure 21. ANOH for various Hysteresis and TTT parameter values at various speeds of EU movements (a) Low speed: 20-60 Kmph, and (b) high-speed: 80-120 Kmph of 41 UEs without considering Fading Effect

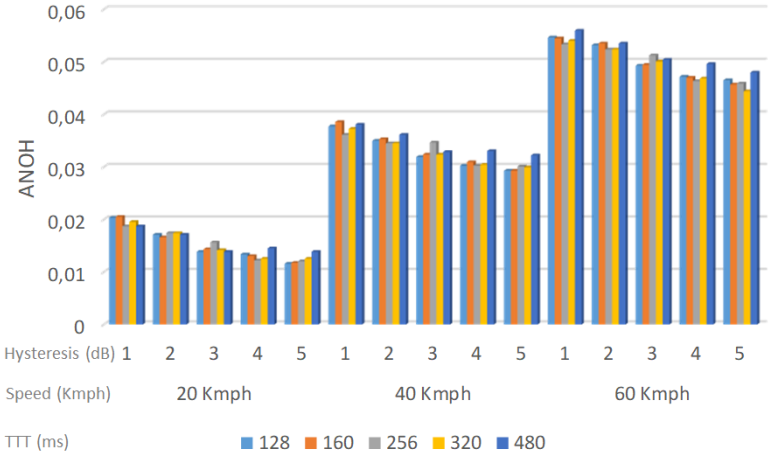

(a)

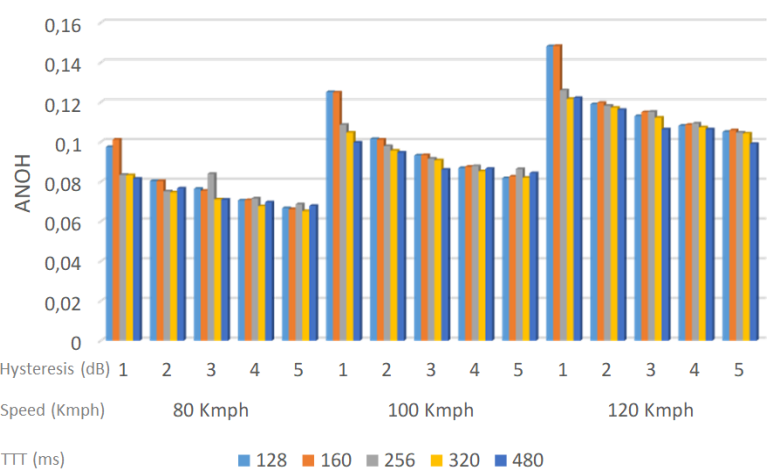

(b)

Figure 22. ANOH for various Hysteresis and TTT parameter values at various speeds of EU movements (a) Low speed: 20-60 Kmph, and (b) high-speed: 80-120 Kmph of 41 UEs by considering Fading Effect.

TABLE 5

SiMULATION RESUlts FOR VARIOUS SCENARIOS FOR THE A3-RSRP ALGORITHM

\begin{tabular}{|c|c|c|c|c|}
\hline \multirow{2}{*}{$\begin{array}{c}\text { UE } \\
\text { Movement } \\
\text { Speed }\end{array}$} & $\begin{array}{c}|c| \\
\text { F1 User }\end{array}$ & \multicolumn{2}{c|}{ 20 User } \\
\cline { 2 - 5 } & $\begin{array}{c}\text { Effect } \\
\text { [Hysteresis;TTT] }\end{array}$ & $\begin{array}{c}\text { Fading } \\
\text { Effect is } \\
\text { not } \\
\text { [Hsteresis;TTT] }\end{array}$ & $\begin{array}{c}\text { Fading } \\
\text { Effect } \\
\text { considered }\end{array}$ & $\begin{array}{c}\text { Fading } \\
\text { Effect } \\
\text { is not } \\
\text { consi- } \\
\text { dered }\end{array}$ \\
\hline $20 \mathrm{kmph}$ & {$[5 ; 256]$} & {$[3 ; 128]$} & {$[5 ; 256]$} & {$[3 ; 128]$} \\
\hline $40 \mathrm{kmph}$ & {$[4 ; 256]$} & {$[5 ; 320]$} & {$[5 ; 160]$} & {$[5 ; 256]$} \\
\hline $60 \mathrm{kmph}$ & {$[5 ; 320]$} & {$[3 ; 256]$} & {$[5 ; 320]$} & {$[3 ; 480]$} \\
\hline $80 \mathrm{kmph}$ & {$[4 ; 160]$} & {$[4 ; 480]$} & {$[5 ; 320]$} & {$[5 ; 480]$} \\
\hline $100 \mathrm{kmph}$ & {$[5 ; 160]$} & {$[3 ; 320]$} & {$[5 ; 160]$} & {$[3 ; 160]$} \\
\hline $120 \mathrm{kmph}$ & {$[5 ; 480]$} & {$[3 ; 256]$} & {$[2 ; 320]$} & {$[5 ; 480]$} \\
\hline
\end{tabular}

From the results, the best Hysteresis and Time-toTrigger (TTT) parameter values for various speed and channel conditions are shown in Table 5.

\section{B. Analysis of Simulation Results}

Simulation results for various scenarios to see the effect of increasing EU speed on the performance of the A3-RSRP and A2-A4-RSRQ algorithms for channel conditions with and without fading are summarized in the form of graphs above. In addition, it can also be seen how the effect of increasing the number of users for various EU movement speeds on performance. In the A3-RSRP algorithm there is a significant decrease with increasing user speed for channel conditions without fading compared to channels with fading. 
Likewise, the same phenomenon occurs for the A2A4-RSRQ algorithm, however the performance of this algorithm is better than the A3-RSRP algorithm. Equally, the effect of increasing the number of users will decrease performance worse on the A3-RSRP algorithm compared to the A2-A4-RSRQ algorithm. The weakness of the A3RSRP algorithm compared to the A2-A4-RSRQ algorithm is because of the ping-pong phenomenon on the A3-RSRP algorithm which is especially noticeable for fading channel conditions. In general, it can be concluded that the performance of A2-A4-RSRQ handover algorithm is better than A3-RSRP handover algorithm.

\section{Handover Parameters Optimization for A2-A4- RSRQ and A3-RSRP Algorithms}

Parameter optimization in the A2-A4-RSRQ algorithm is intended to find the most optimum Serving Cell Thershold and Cell Offset Neighbour values that provide the best ANOH value. Graph in Figure 23 shows a plot of the Optimize Ratio as a function of Serving Cell Thershold and Cell Offset Neighbour. From the graph it can be identified that the value of Serving Cell Thershold and Cell Offset Neighbour which gives the most optimum ANOH value are $30 \mathrm{~dB}$ and $10 \mathrm{~dB}$ respectively.

On the other hand, parameter optimization in the A3RSRP algorithm is intended to find the most optimum Hysteresis and TTT values that provide the best ANOH value. Graph in Figure 24 shows a plot of the Optimize Ratio as a function of Hysteresis and TTT. From the graph it can be identified that the value of Hysteresis and TTT which gives the most optimum ANOH value are 12 $\mathrm{dB}$ and $480 \mathrm{~ms}$ respectively.

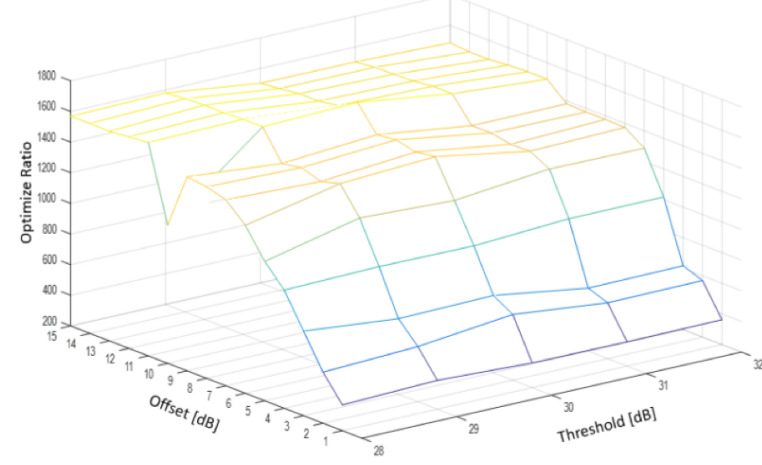

Figure 23. The value of Optimize Ratio as a function of Offset and Threshold for the A2-A4-RSRQ algorithm.

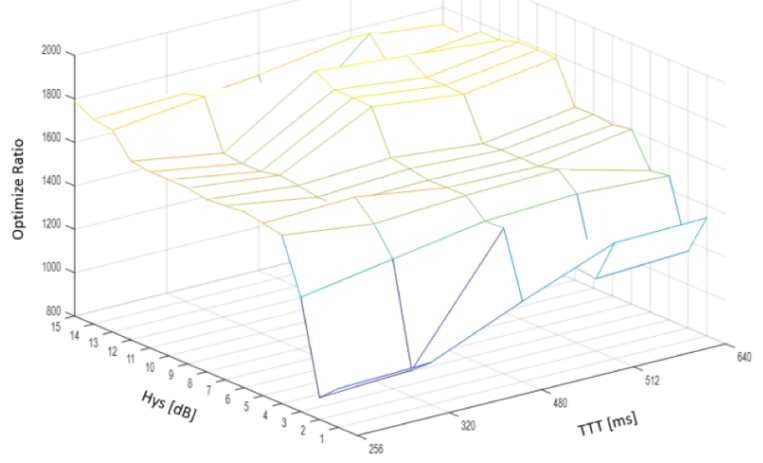

Figure 24. The value of Optimize Ratio as a function of Hysteresis and TTT for the A3-RSRP algorithm
TABLE 6

COMPARISON OF MEASUREMENT RESUlTS AND SiMULATION RESULTS OF RSRP AND RSRQ ALGORITHMS

\begin{tabular}{|c|c|c|c|}
\hline Parameter & Measurement & $\begin{array}{c}\text { RSRP } \\
\text { Algorithm }\end{array}$ & $\begin{array}{c}\text { RSRQ } \\
\text { Algorithm }\end{array}$ \\
\hline $\begin{array}{c}\text { Troughput } \\
\text { (Mbps) }\end{array}$ & 15.223 & 15.98 & 15.721 \\
\hline ANOH & 0.014130435 & 0.010869565 & 0.025 \\
\hline $\begin{array}{c}\text { Optimize } \\
\text { Ratio }\end{array}$ & 1077.32 & 1470.16 & 628.84 \\
\hline
\end{tabular}

\section{Comparison of Measurement and Simulation Results}

The network that was evaluated by direct measurements in the field is set at the TTT parameter value of $480 \mathrm{~ms}$ and Hysteresis value of $2 \mathrm{~dB}$ for the A3RSRP algorithm, in the same way, is set at the Threshold value of $30 \mathrm{~dB}$ and Offset value of $2 \mathrm{~dB}$ for the A2-A4RSRQ algorithm. Performance metrics observed are Throughput value, Average Number of Handover (ANOH) and Optimized Ratio. Comparison of measurement results with simulation results is presented in Table 6.

From Table 6, it can be seen that the measurement results are not exactly the same as the simulation results, but give a value that is close enough. The measurement results and simulations for the RSRP algorithm provide closer values compared to the RSRQ algorithm. Therefore, the simulations for the RSRP algorithm provide more accurate results which better represent the true value of the measurement results.

\section{CONCLUSION}

In this study, the performance of the A2-A4-RSRQ and A3-RSRP algorithms was evaluated through simulation and measurement. For a variety of scenarios from the simulation, the best handover parameter values are obtained which give the best system performance. The results of the simulation also provide values that are not much different from the measurement results especially for RSRP-based algorithms. Therefore, a simulation is then performed to find the HO parameter values which gives the best performance for the scenario where each EU has a random speed in the range of 20 to $120 \mathrm{KmPh}$. It has been shown that, for the A3-RSRP algorithm a combination of TTT value of $480 \mathrm{~ms}$ and Hysteresis of $12 \mathrm{~dB}$ gives the best $\mathrm{HO}$ performance, while for the RSRQ algorithm the combination of Neighbour Cell Offset of $10 \mathrm{~dB}$ and Serving Cell Threshold of $30 \mathrm{dBm}$ gives the best $\mathrm{HO}$ performance.

\section{REFERENCES}

[1] 3GPP TS 36.300 V9.5.0 (2010-09), Evolved Universal Terrestrial Radio Access (E-UTRA) and Evolved Universal Terrestrial Radio Access Network (E-UTRAN); overall description; Stage 2 (Release 9), 2010.

[2] 3GPP, TSG Services and System Aspects; KPI for Evolved Universal Terrestrial Radio Access Network (EUTRAN); Requirements (Release 12), 3GPP TS 32.451 V12.0.0, October 2014.

[3] F. Khan, LTE for $4 G$ Mobile Broadband Air Interface Technologies and Performance, Cambridge University Press, 
2009.

[4] K. Alexandris, N. Nikaein, R. Knopp, and C. Bonnet, "Analyzing X2 Handover in LTE/LTE-A," in Proc. 14th International Symposium on Modelling and Optimization in Mobile, Ad Hoc and Wireless Networks (WiOpt), May 2016, doi: 10.1109/WIOPT.2016.7492906.

[5] S. Sesia, I. Touk, M. Baker, LTE-The UMTS long Term Evolution: From Theory to Practice, John Wiley \& Sons Ltd, 2009.

[6] C.-C. Lin, K. Sandrasegaran, H.A.M. Ramli, and R. Basukala, "Optimized Performance Evaluation Of LLE Hard Handover Algorithm With Average RSRP Constraint," International Journal of Wireless \& Mobile Networks (IJWMN), vol. 3, no. 2 , April 2011

[7] T. Jansen, I. Balan, J. Turk, I. Moerman, T. Kurner, "Handover Parameter Optimization in LTE Self-Organizing Networks," in Proc. 2010 IEEE 72nd Vehicular Technology Conference, Sept. 2010, doi: 10.1109/VETECF.2010.5594245

[8] B. Herman, D. Petrov, J. Puttonen, J. Kurjenniemi, "A3-Based Measurements and Handover Model for NS-3 LTE," in Proc. The Third International Conference on Mobile Services, Resources, and Users, Lisboa, 2013.

[9] M. Hussein, S. Primak, A. Shami, "Intra-MME/S-GW handover performance analysis in virtualized 3GPP-LTE systems," in Proc. 2016 IEEE Canadian Conference on Electrical and Computer Engineering (CCECE), 2016, pp. 1-4, doi: 10.1109/CCECE.2016.7726646.

[10] J. C. Chaparro-Marroquín, "Comparison between measurement events for LTE handover in rural and urban scenarios involving femto-cell deployment," Latest Trends on Communications, 2014

[11] E.A. Ibrahim, M.R.M. Rizk, E.F. Badran, "Study of LTE-R X2
Handover based on A3 event Algorithm using MATLAB," in Proc. 2015 International Conference on Information and Communication Technology Convergence (ICTC), 2015, doi: 10.1109/ICTC.2015.7354762.

[12] L. Zhang, T. Okamawari and T. Fujii, "Performance Evaluation of TCP and UDP during LTE Handover," in Proc. 2012 IEEE Wireless Communications and Networking Conference (WCNC), 2012, doi: 10.1109/WCNC.2012.6214116.

[13] J.B.I. Chavarría, "LTE Handover Performance Evaluation Based on Power Budget Handover Algorithm," M.S. Thesis, Universitat Politècnica de Cataluña, 2014.

[14] H.-C. Chen, and Y. Cahyadi, "A Grey Prediction Based Hard Handover Hysteresis Algorithm for 3GPP LTE System," in Proc. 2012 Seventh International Conference on Broadband, Wireless Computing, Communication and Applications, 2012, doi: 10.1109/BWCCA.2012.103

[15] R.D. Hegazy and O.A. Nasr, "A User Behaviour Based Handover Optimization Algorithm for LTE Networks," in Proc. 2015 IEEE Wireless Communications and Networking Conference (WCNC), 2015, doi: 10.1109/WCNC.2015.7127649

[16] N. Baldo, M. Requena-Esteso, M. Miozzo, “An Open Source Model for the Simulation of LTE Handover Scenarios and Algorithms in ns-3," in Proc. The 16th ACM international conference on Modelling, analysis and simulation of Wireless and mobile systems, Barcelona, Spain, Nov. 2013, pp. 289-298.

[17] 3GPP TS 36.104 V12.10.0 (2016-01), Annex B.2, 3rd Generation Partnership Project; Technical Specification Group Radio Access Network; Evolved Universal Terrestrial Radio Access (EUTRA); Base Station (BS) radio transmission and reception (Release 12). 